\title{
Synthesis of a Ce-Based MOF-76 with High Yield: A Study of Reaction Parameters Based on a Factorial Design
}

\author{
Patricia F. Santos ${ }^{\circledR *, a}$ and Priscilla P. Luz ${ }^{\circledR *, a}$ \\ ${ }^{a}$ Departamento de Química, Universidade Federal do Espírito Santo, 29075-910 Vitória-ES, Brazil
}

\begin{abstract}
The purpose of this work was to optimize the synthesis yield of $\left\{\left[\mathrm{Ce}(\mathrm{BTC})\left(\mathrm{H}_{2} \mathrm{O}\right)\right] \cdot \mathrm{DMF}\right\}_{\mathrm{n}}, \mathrm{a}$ metal-organic framework (MOF)-76 family member, by solvothermal method. $\mathrm{CeCl}_{3} \cdot 7 \mathrm{H}_{2} \mathrm{O}$ and 1,3,5-benzenetricarboxylic acid, 2:1 molar proportion, were added to $\mathrm{N}, \mathrm{N}$-dimethylformamide (DMF). Reaction time and temperature were evaluated to optimize the synthesis through a factorial design followed by a statistical analysis of the response variable (reaction yield). Infrared spectroscopy (IR), X-ray diffraction (XRD), thermogravimetric analysis (TGA), scanning electron microscopy (SEM) and Brunauer-Emmett-Teller (BET) analyses were performed to characterize the obtained white powders. Reaction yield was estimated based on $\left\{\left[\mathrm{Ce}(\mathrm{BTC})\left(\mathrm{H}_{2} \mathrm{O}\right)\right] \cdot \mathrm{DMF}\right\}_{\mathrm{n}}$ molecular formula, which was confirmed by analytical techniques. The proposed statistic model of the response variable showed good agreement with the experimental values. Temperature parameter was the only significant variable on the reaction yields, being the highest yield (94.4\%) obtained at $115^{\circ} \mathrm{C}$ for $36 \mathrm{~h}$, and it was accompanied by an improvement on the particle morphology (uniformity of shape and size), forming particles with strawsheave-like morphology.
\end{abstract}

Keywords: cerium, BTC, MOF-76, factorial design

\section{Introduction}

New materials have attracted interest from researchers due to their potential applications in many areas of science and technology. Over past few decades, compounds formed by an inorganic-organic hybrid structure have impacted the porous materials field, resulting in a group characterized by a metal-organic structure, called metal-organic frameworks (MOFs). ${ }^{1-3}$

MOFs represent a new class of materials composed of metal centers linked by multi-dentate organic molecules as bridging ligands. Many organic and inorganic compounds can be employed to construct MOFs. Normally, group of aromatic carboxylate linkers are used, such as terephthalic acid (1,4-benzenedicarboxylic acid or its carboxylate form named BDC) and trimesic acid (1,3,5-benzenetricarboxylic acid, or $\mathrm{H}_{3} \mathrm{BTC}$, or BTC), with two and three carboxylate groups, respectively, which provide high thermal stability and rigidity to the final MOF structure. The metallic center can be constituted by a metallic ion or by a cluster. Among all the possibilities of metals, lanthanides are required for MOF construction due to their large coordinating sphere, which enables the coordination of many linkers

*e-mail: patriciafigs@hotmail.com; priscilla.luz@ufes.br with different sizes and solvent molecules. Thus, when performing a heat treatment, it is possible to remove the auxiliary ligands creating active sites (Lewis acid), which are essential for catalysis application..$^{2-4}$

MOFs are open networks that exhibit crystalline structures, different pore sizes (micro and mesoporous), open metallic sites, active functional groups, low density and large surface area..$^{4-6}$ Due to this diversity of structures, MOFs have been applied in different areas, such as catalytic reactions, ${ }^{1}$ gas storage, ${ }^{3}$ luminescent sensors, ${ }^{7}$ drug delivery,${ }^{8,9}$ ion exchange,${ }^{10}$ and component separation. ${ }^{11}$

MOF-76 represents a family of compounds formed by lanthanide ions and BTC as linker, which was firstly synthesized by Rosi et al. ${ }^{12}$ and since then it had been synthesized and studied for different applications. ${ }^{12-15}$ Specifically a MOF-76 of cerium, $\mathrm{Ce}^{3+}$-based MOF-76, $\left\{\left[\mathrm{Ce}(\mathrm{BTC})\left(\mathrm{H}_{2} \mathrm{O}\right)\right] \cdot \mathrm{DMF}\right\}_{\mathrm{n}}$, has been synthesized by Almáši et al., ${ }^{1}$ Chevinly et al. ${ }^{11}$ Peng et al. ${ }^{16}$ and Zhang et al. ${ }^{17,18}$ by solvothermal method, reacting a hydrated cerium salt with BTC ligand in $N, N$-dimethylformamide (DMF), used as solvent. In their works, the reaction parameters applied in $\left\{\left[\mathrm{Ce}(\mathrm{BTC})\left(\mathrm{H}_{2} \mathrm{O}\right)\right] \cdot \mathrm{DMF}\right\}_{\mathrm{n}}$ synthesis, such as time and temperature, were not evaluated, but there were variations of these parameters between 
these works. For instance, Almáši et al. ${ }^{1}$ synthesized the $\left\{\left[\mathrm{Ce}(\mathrm{BTC})\left(\mathrm{H}_{2} \mathrm{O}\right)\right] \cdot \mathrm{DMF}\right\}_{\mathrm{n}}$ at $100{ }^{\circ} \mathrm{C}$ for $60 \mathrm{~h}$ and subsequently tested its catalytic activity in a condensation reaction. Chevinly et al. ${ }^{11}$ synthesized it at $100{ }^{\circ} \mathrm{C}$ for $17 \mathrm{~h}$ and tested its neodymium ion adsorption capacity. Peng et al. ${ }^{16}$ performed the synthesis of $\{[\mathrm{Ce}(\mathrm{BTC})$ $\left.\left.\left(\mathrm{H}_{2} \mathrm{O}\right)\right] \cdot \mathrm{DMF}\right\}_{\mathrm{n}}$ at $130{ }^{\circ} \mathrm{C}$ for $24 \mathrm{~h}$ and tested its oxidative capacity. Zhang et al..$^{17,18}$ synthesized the $\mathrm{Ce}^{3+}$-based MOF-76 based at $130{ }^{\circ} \mathrm{C}$ for $24 \mathrm{~h}$ and used this MOF as precursor for $\mathrm{CeO}_{2}$ production, with the purpose of optimizing the oxide catalytic capacity, as a consequence of its morphology predicted by MOF structure. $\mathrm{Ce}^{3+}$-based MOF-76 has also been synthesized by Elhussein et al. ${ }^{19}$ by hydrothermal method, in a water:ethanol medium, at $60^{\circ} \mathrm{C}$ for $1 \mathrm{~h}$. Zeng et al. ${ }^{20}$ performed the same synthesis at room temperature for $10 \mathrm{~min} .{ }^{20}$

All the mentioned works reporting the conditions for obtaining the $\mathrm{Ce}^{3+}$-based MOF-76 kept fixed their reaction parameters and did not perform a study aiming to optimize their synthesis. Understanding the influence of reaction parameters is important, since they can significantly impact on the reaction yield, particles morphology, structure and chemical composition of the goal compounds, reducing costs or chemicals, improving properties, or directing them to the convenient application. Among theses works, only Almáši et al. ${ }^{1}$ reported the reaction yield, $56 \%$, which is considerably low considering the energy expenditure during $60 \mathrm{~h}$ at $100^{\circ} \mathrm{C}$.

Therefore, this work was focused on the optimization of $\left\{\left[\mathrm{Ce}(\mathrm{BTC})\left(\mathrm{H}_{2} \mathrm{O}\right)\right] \cdot \mathrm{DMF}\right\}_{\mathrm{n}}$ solvothermal synthesis through a three-level factorial design. Time and temperature were the evaluated factors, the reaction yield was the response variable and DMF was the solvent. Crystallinity, thermal stability and particles characteristics were also evaluated.

\section{Experimental}

\section{Chemical materials}

Cerium(III) chloride heptahydrate $\left(\mathrm{CeCl}_{3} .7 \mathrm{H}_{2} \mathrm{O}\right)$ (99.9\%, Aldrich $^{\circledast}$, St. Louis, USA), H 3 BTC (95\%, Aldrich $^{\circledast}$, St. Louis, USA) and DMF (99.8\%, Êxodo Científica ${ }^{\circledR}$, Hortolândia, Brazil) were commercially available and used without prior purification.

Synthesis of $\left\{\left[\mathrm{Ce}(\mathrm{BTC})\left(\mathrm{H}_{2} \mathrm{O}\right)\right] \cdot \mathrm{DMF}\right\}_{\mathrm{n}}$

$\mathrm{CeCl}_{3} .7 \mathrm{H}_{2} \mathrm{O}(0.2 \mathrm{mmol}), \mathrm{H}_{3} \mathrm{BTC}(0.1 \mathrm{mmol})$ and $20.0 \mathrm{~mL}$ DMF were added into a $40 \mathrm{~mL}$ sealed-Teflon reactor. Then, the system was heated to 100,115 or $130^{\circ} \mathrm{C}$, at a heating rate of $2.0^{\circ} \mathrm{C} \mathrm{min}^{-1}$, and kept for 12,24 or $36 \mathrm{~h}$. As it is possible to see, the reaction parameters time and temperature were varied, generating nine syntheses from combinations between them. At the end of each synthesis, the reaction mixture was cooled down to room temperature at a cooling rate of $2.0^{\circ} \mathrm{C} \mathrm{min}^{-1}$. Polycrystalline materials of $\left\{\left[\mathrm{Ce}(\mathrm{BTC})\left(\mathrm{H}_{2} \mathrm{O}\right)\right] \cdot \mathrm{DMF}\right\}_{\mathrm{n}}$, shortly named Ce-BTC, were isolated by centrifugation, washed with $\mathrm{DMF}$, and dried in a vacuum oven at $80{ }^{\circ} \mathrm{C}$ for $24 \mathrm{~h}$.

\section{Statistical analysis of the response variable}

As mentioned on "Synthesis of $\left\{\left[\mathrm{Ce}(\mathrm{BTC})\left(\mathrm{H}_{2} \mathrm{O}\right)\right] \cdot \mathrm{DMF}\right\}_{\mathrm{n}}$ " sub-section, the reaction parameters time and temperature were varied according to a three-level (lower $(-1)$, average (0) and upper (+1) levels) full factorial design (Table 1) to optimize the Ce-BTC reaction yield.

Table 1. Factorial design variables (time and temperature) and their respective values for lower $(-1)$, average $(0)$ and upper $(+1)$ levels

\begin{tabular}{lcc}
\hline Experiment $($ name $)$ & time $/ \mathrm{h}$ & Temperature $/{ }^{\circ} \mathrm{C}$ \\
\hline $1\left(\mathrm{Ce}-\mathrm{BTC} 12 \mathrm{~h} 100^{\circ} \mathrm{C}\right)$ & $12(-1)$ & $100(-1)$ \\
$2\left(\mathrm{Ce}-\mathrm{BTC} 24 \mathrm{~h} 100{ }^{\circ} \mathrm{C}\right)$ & $24(0)$ & $100(-1)$ \\
$3\left(\mathrm{Ce}-\mathrm{BTC} 36 \mathrm{~h} 100^{\circ} \mathrm{C}\right)$ & $36(+1)$ & $100(-1)$ \\
$4\left(\mathrm{Ce}-\mathrm{BTC} 12 \mathrm{~h} 115^{\circ} \mathrm{C}\right)$ & $12(-1)$ & $115(0)$ \\
$5\left(\mathrm{Ce}-\mathrm{BTC} 24 \mathrm{~h} 115^{\circ} \mathrm{C}\right)$ & $24(0)$ & $115(0)$ \\
$6\left(\mathrm{Ce}-\mathrm{BTC} 36 \mathrm{~h} 115^{\circ} \mathrm{C}\right)$ & $36(+1)$ & $115(0)$ \\
$7\left(\mathrm{Ce}-\mathrm{BTC} 12 \mathrm{~h} 130^{\circ} \mathrm{C}\right)$ & $12(-1)$ & $130(+1)$ \\
$8\left(\mathrm{Ce}-\mathrm{BTC} 24 \mathrm{~h} 130^{\circ} \mathrm{C}\right)$ & $24(0)$ & $130(+1)$ \\
$9\left(\mathrm{Ce}-\mathrm{BTC} 36 \mathrm{~h} 130^{\circ} \mathrm{C}\right)$ & $36(+1)$ & $130(+1)$ \\
\hline $\mathrm{Ce}-\mathrm{BTC}:(\mathrm{Ce}(\mathrm{BTC})(\mathrm{H})$ &
\end{tabular}

Ce-BTC: $\left\{\left[\mathrm{Ce}(\mathrm{BTC})\left(\mathrm{H}_{2} \mathrm{O}\right)\right] \cdot \mathrm{DMF}\right\}_{\mathrm{n}}$.

Statistical treatment of the reaction yields data was carried out using Statistica software. ${ }^{21}$ This statistical treatment is based on the analysis of the influence of each factor (time and temperature) on the response variable (reaction yield). The predicted reaction yield values $(\hat{y})$ were calculated based on the model:

$\hat{y}\left(x_{1}, x_{2}\right)=b_{0}+b_{1} x_{1}+b_{1} x_{1}^{2}+b_{2} x_{2}+b_{2} x_{2}^{2}$

being $\mathrm{b}$ the reaction parameters coefficient, $\mathrm{x}_{1}=$ reaction time and $x_{2}=$ temperature. The standard error (Std. Err.) was calculated based on prediction error (e) from model:

$\mathrm{e}=\mathrm{y}-\hat{\mathrm{y}}$

being y the experimental reaction yield. Standard error and $p$-value were used to determine the significance of coefficients model b's. 


\section{Characterization of Ce-BTC}

Crystal structure was analyzed by powder X-ray diffraction (PXRD) on a diffractometer (D8 Discover, Bruker $^{\mathrm{TM}}$ ) using $\mathrm{Cu} \mathrm{K} \alpha$ radiation $(\lambda=1.54056 \AA), 2 \theta$ range of $5-50^{\circ}$, angular step of $2^{\circ}$, at $40 \mathrm{kV}$, and $40 \mathrm{~mA}$.

Coordination mode and chemical bonds were evaluated by Fourier-transform infrared spectroscopy (FTIR) in attenuated total reflectance (ATR) mode on a spectrometer (Cary 630 FTIR, Agilent). Spectra were recorded at room temperature, with a resolution of $2 \mathrm{~cm}^{-1}$ and 32 scans, between 4000 and $650 \mathrm{~cm}^{-1}$.

Thermal stability was evaluated by thermogravimetric analysis (TGA) on a thermogravimetric analyzer (TGA-50, Shimadzu ${ }^{\mathrm{TM}}$ ). The analysis was carried out with approximately $3 \mathrm{mg}$ of samples, under argon atmosphere, flow rate of $70.00 \mathrm{~mL} \mathrm{~min}^{-1}$, heated from room temperature to $700{ }^{\circ} \mathrm{C}$ at a heating rate of $10^{\circ} \mathrm{C} \mathrm{min}^{-1}$.

Particles morphology was studied by scanning electron microscopy (SEM) on a microscope (SUPERSCAN SS-550, Shimadzu ${ }^{\mathrm{TM}}$ ). Prior measuring, the samples were sputter-coated with a thick gold film and then examined at $15 \mathrm{kV}$.

Brunauer-Emmett-Teller $(\mathrm{BET})$ surface area $\left(\mathrm{S}_{\mathrm{BET}}\right)$ from nitrogen isotherms were taken on a gas sorption analyzer (Autosorb-1, QuantaChrome Instruments ${ }^{\circledR}$ ). The sorption properties were obtained from a weight within $20-30 \mathrm{mg}$ of compounds synthesized at 100,115 and $130{ }^{\circ} \mathrm{C}$ for 36 h. $\mathrm{S}_{\mathrm{BET}}$ were evaluated using relative pressure range of $5.7 \times 10^{-2}$ to $3.1 \times 10^{-1}$. The samples were degassed in a vacuum chamber for $4 \mathrm{~h}$ at $90{ }^{\circ} \mathrm{C}$ before BET analysis.

\section{Results and Discussion}

\section{Statistical analysis of the response variable}

The factorial design was executed according to the reaction procedure described previously and the results of yield reaction are shown in Table 2. In general, the reaction yield was proportional to reaction time and temperature (up
Table 2. Results of yield reaction based on factorial design variables (time and temperature) in three levels

\begin{tabular}{lccc}
\hline \multirow{3}{*}{ time / h } & \multicolumn{3}{c}{ Yield / \% } \\
\cline { 2 - 4 } & $100{ }^{\circ} \mathrm{C}$ & $115^{\circ} \mathrm{C}$ & $130{ }^{\circ} \mathrm{C}$ \\
\hline 12 & 40.89 & 83.77 & 72.00 \\
24 & 45.78 & 91.11 & 82.22 \\
36 & 36.88 & 94.44 & 87.77 \\
\hline
\end{tabular}

to $115^{\circ} \mathrm{C}$ ), but the temperature exhibited a greater influence over the response variable, which is understandable since as the temperature increases, the average kinetic energy of molecules also increases and a greater amount of molecules acquire sufficient energy to react. At $115^{\circ} \mathrm{C}$, the reaction yields were very satisfactory at all times, being superior to $56 \%$ reported by Almáši et al. ${ }^{1}$ The factors were synergistic at a certain extent and the highest reaction yield (94.5\%) was achieved at $115^{\circ} \mathrm{C}$ and $36 \mathrm{~h}$.

The table of effects (Table 3), generated by Statistica software, ${ }^{21}$ presented data within a $95 \%$ confidence limit and revealed the influence of each factor on the response variable and the interaction between them. In addition, it displays $p$-values, which describe the significance of the result. A factor whose $p$-value is lower than $5 \%$ is considered significant. In this sense, from Table 3, the response variable was influenced by the interaction between the two factors and by the temperature factor, linear and quadratic way. Despite the lower contribution of the time factor in the response variable, it contributed positively to the increase of the reaction yield.

To analyze the interference of parameters time and temperature in the reaction yield of Ce-BTC syntheses, a mathematical model was constructed with interactions between the two factors at three levels. The coefficient of determination $\left(\mathrm{R}^{2}\right)$ was 0.97 and the coefficients values (Table 3 ) allowed fitting a regression model based on:

$\hat{y}\left(x_{1}, x_{2}\right)=70.54+19.74 x_{1}+14.43 x_{1}^{2}+3.74 x_{2}+1.87 x_{2}^{2}$

which can be summarized as:

Table 3. Table of effects for the factorial design of Ce-BTC synthesis

\begin{tabular}{|c|c|c|c|c|c|}
\hline Variable & Effect & Coeff. & Std. Err. & $p$-Value & $t$-Test \\
\hline Mean/interactions & 70.54 & 70.54 & 1.79 & $2 \times 10^{-6}$ & 39.39 \\
\hline Temperature (L) $/{ }^{\circ} \mathrm{C}$ & 39.48 & 19.74 & 2.19 & $8 \times 10^{-4}$ & 9.00 \\
\hline Temperature (Q) $/{ }^{\circ} \mathrm{C}$ & 28.85 & 14.43 & 1.90 & 0.002 & 7.59 \\
\hline time $(\mathrm{L}) / \mathrm{h}$ & 7.48 & 3.74 & 2.19 & 0.16 & 1.70 \\
\hline time $(\mathrm{Q}) / \mathrm{h}$ & 3.75 & 1.87 & 1.90 & 0.38 & 0.98 \\
\hline
\end{tabular}

Coeff.: coefficient; Std. Err.: standard error; L: linear; Q: quadratic. 
$\hat{\mathrm{y}}\left(\mathrm{x}_{1}, \mathrm{x}_{2}\right)=70.54+19.74 \mathrm{x}_{1}+14.43 \mathrm{x}_{1}^{2}$

The obtained yields for Ce-BTC syntheses showed good proximity with the predicted yields, as presented in Figure 1, indicating a good agreement to the model.

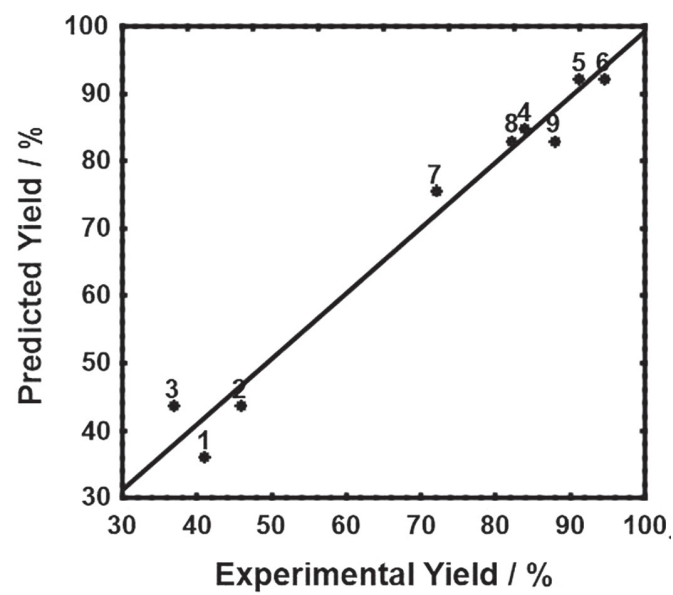

Figure 1. Experimental yield against predicted yield for synthesized Ce-BTC compounds.

The response surface graph (Figure 2), generated by Statistica Software, ${ }^{21}$ allowed a visual analysis of the reaction yields on a uniform surface. The interaction of independent variables located on $x$ and $y$ axes, temperature and time, respectively, resulted in the response variable, which lied on $z$ axis. Figure 2 confirmed the synergism between temperature and time up to $115{ }^{\circ} \mathrm{C}$ and revealed the conditions for achieving high yield values.

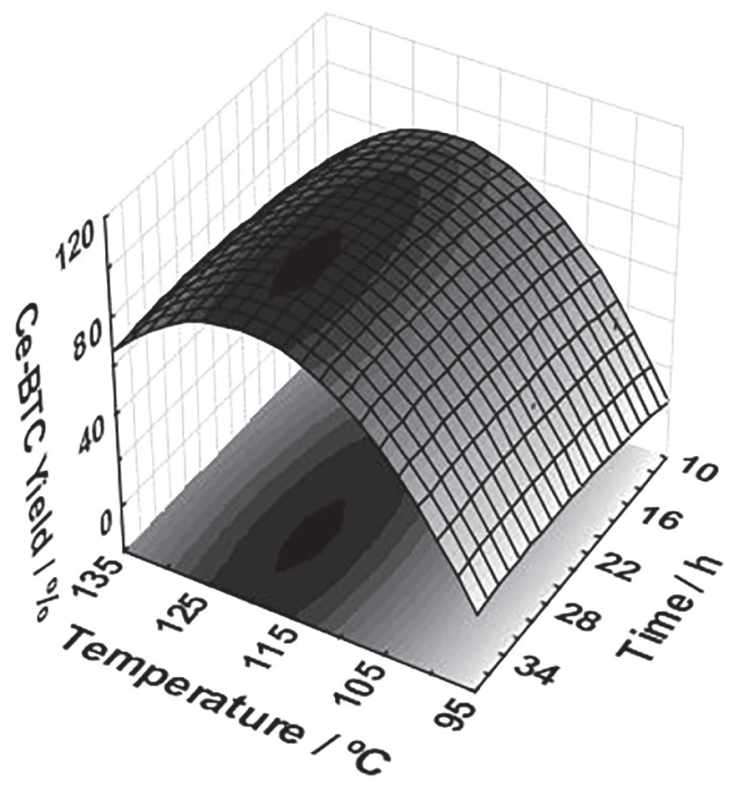

Figure 2. Response surface graph of the factorial design for Ce-BTC synthesis.

\section{Structural characterization}

The crystal structure of all synthesized Ce-BTC was determined comparing the PXRD results to deposited crystallographic structures of MOF-76, by Almáši et al. ${ }^{3}$ and Luo et al. ${ }^{22}$ which were used to simulate the theoretical pattern of XRD by employing VESTA program. ${ }^{23}$ Almáši et al. ${ }^{3}$ synthesized two structures from holmium and thulium with BTC as linker, $\left\{\left[\mathrm{Ho}(\mu 6-\mathrm{BTC})\left(\mathrm{H}_{2} \mathrm{O}\right)\right] \cdot \mathrm{DMF}\right\}_{\mathrm{n}}$ and $\left\{\left[\operatorname{Tm}(\mu 6-\mathrm{BTC})\left(\mathrm{H}_{2} \mathrm{O}\right)\right] \cdot \mathrm{DMF}\right\}_{\mathrm{n}}$, respectively, and Luo et al. ${ }^{22}$ synthesized a MOF-76 from yttrium. These three deposited structure are isostructural, display tetragonal crystalline system, but different space groups $\mathrm{P}_{3}, \mathrm{P}_{1} 22$ and $\mathrm{P}_{3} 22$, respectively. ${ }^{3,22}$

PXRD patterns of the synthesized Ce-BTC compounds matched the simulated (theoretical) patterns, indicating a successful production of compounds with MOF-76 structure, as shown in Figure 3. According to diffractograms reported in the literature, MOF-76 family displays, among others, two characteristic peaks at 8.4 and $10.6^{\circ}$, which were exhibited by the synthesized Ce-BTC, besides presenting the next two peaks, at 12 and $13.4^{\circ}$, similar to those peaks presented by the authors (Figure 3). ${ }^{1,3,17,18,24,25}$ As a consequence, it was possible to assume the $\mathrm{Ce}^{3+}$ ions were hepta-coordinated to oxygen atoms, one of them from a water molecule, forming a coordination polyhedron described as pentagonal bipyramid. ${ }^{3}$ The unit cell was formed by the tetragonal crystalline system $(\alpha=90, \beta=90, \gamma=90 ; a=b \neq c)$ with 4 asymmetric units and $152 \AA^{3}$, approximately. $3,22,26$ The following peaks are slightly displaced and those mismatching might be attributed to: $(i)$ differences between the ionic radius of synthesized samples (based on $\mathrm{Ce}^{3+}$ ) and compounds of simulated single crystal pattern (based on $\mathrm{Ho}^{3+}$ and $\mathrm{Tm}^{3+}$ ) and (ii) the employed synthesis procedure, since the heating on the solvothermal is not uniform across the reactor vessel. Chuasaard et al. ${ }^{27}$ evaluated the structural variation of lanthanide coordination polymers produced by microwave and conventional heating methods. The microwave heating apparently led to the formation of the isostructural compounds across the studied trivalent lanthanide series ( $\mathrm{Pr}, \mathrm{Nd}, \mathrm{Sm}, \mathrm{Eu}$ and $\mathrm{Gd})$. However, changes in the crystal structures along the lanthanide series and for the same metal ion were observed when conventional heating was applied as a synthesis method. ${ }^{27}$

FTIR spectra acquired for all synthesized Ce-BTC compounds are presented in Figure S1 (Supplementary Information (SI) section). There was no significant difference between them and they showed bands similar to those performed by Almáši et al. ${ }^{1}$ and Peng et al..${ }^{16}$ who synthesized MOFs with the cerium metal, being another indicative of success in producing a Ce-based MOF-76. In 


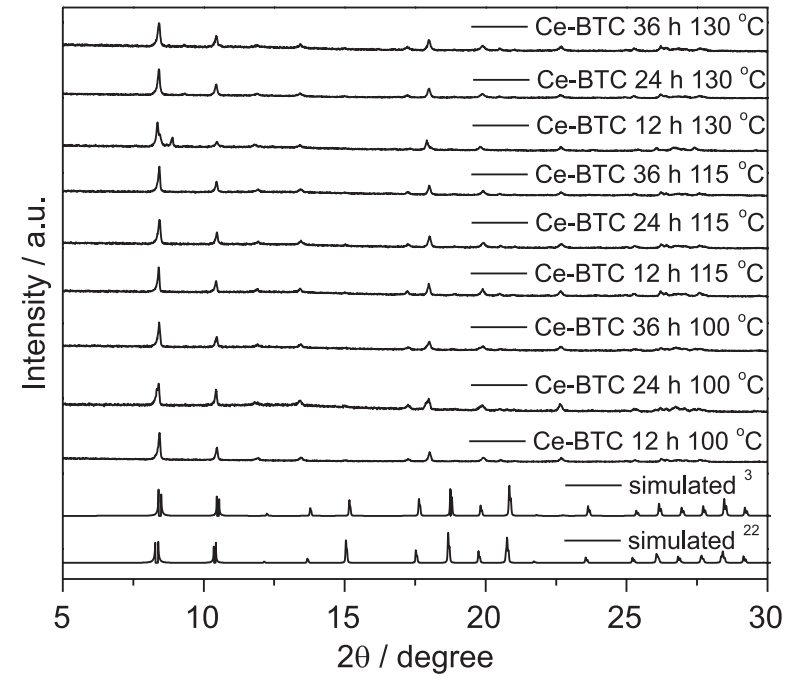

Figure 3. PXRD pattern of as-synthesize Ce-BTC compounds and simulated data from deposited structures. ${ }^{3,22}$

this sense, the sample Ce-BTC $36 \mathrm{~h} 130{ }^{\circ} \mathrm{C}$ was selected as representative and its IR spectrum is shown in Figure 4, as well $\mathrm{H}_{3} \mathrm{BTC}$ IR spectrum.

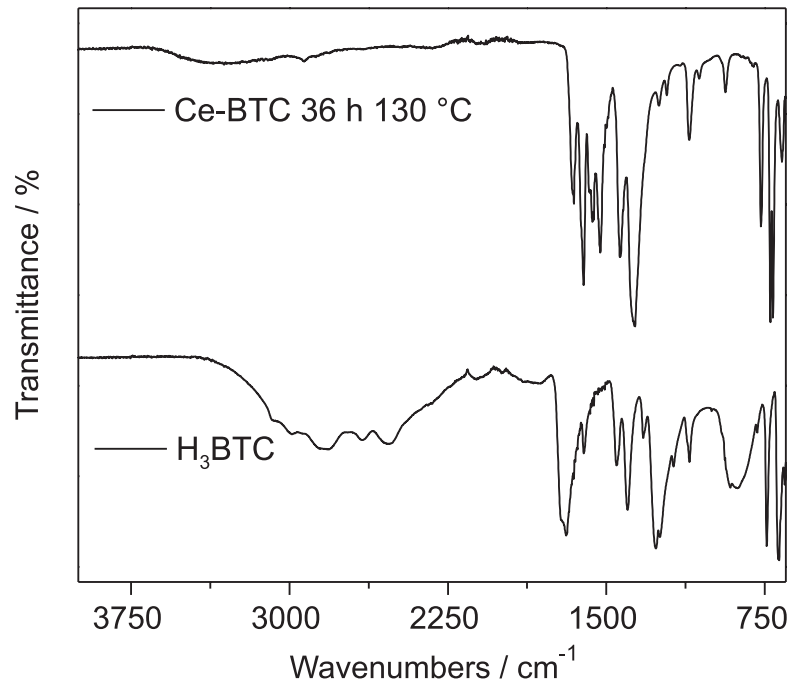

Figure 4. IR spectra (ATR) of Ce-BTC $36 \mathrm{~h} 130^{\circ} \mathrm{C}$ and free $\mathrm{H}_{3} \mathrm{BTC}$.

Ce-BTC $36 \mathrm{~h} 130^{\circ} \mathrm{C}$ IR spectrum (Figure S2, SI section) exhibited characteristic bands of BTC, DMF and water. The band at $3400 \mathrm{~cm}^{-1}$ was assigned to $v(\mathrm{O}-\mathrm{H})$ vibration of the coordinated water molecule, corroborating the PXRD result, probably originated from the hydrated cerium salt. ${ }^{28}$ The symmetric $v_{\mathrm{s}}(\mathrm{CH})$ and asymmetric $v_{\mathrm{as}}(\mathrm{CH})$ vibrations of methyl groups from DMF were observed at 2874 and $2933 \mathrm{~cm}^{-1}$, respectively, as well a strong band at $1655 \mathrm{~cm}^{-1}$ assigned to $v(\mathrm{C}=\mathrm{O})$ of amide confirmed the presence of solvent retained in the channels of MOF structure. ${ }^{1,3,17,28}$ The presence of the $\mathrm{BTC}$ coordinated to $\mathrm{Ce}^{3+}$ ion was confirmed by the absence of $v(\mathrm{C}=\mathrm{O})$ band at $1714 \mathrm{~cm}^{-1}$, corresponding to $\mathrm{H}_{3} \mathrm{BTC}$ carboxylic group, which was substituted by the characteristic bands of carboxylate group in the Ce-BTC $36 \mathrm{~h} 130{ }^{\circ} \mathrm{C}$ spectrum, commonly assigned at $1607 \mathrm{~cm}^{-1}$ for the $v_{\mathrm{as}}\left(\mathrm{COO}^{-}\right)$vibration and at 1438 and $1367 \mathrm{~cm}^{-1}$ for the $v_{\mathrm{s}}\left(\mathrm{COO}^{-}\right)$vibration. ${ }^{29}$ The presence of BTC in the synthesized compounds was also confirmed by the presence of three aromatic ring bands: at $3100 \mathrm{~cm}^{-1}$ attributed to $v(\mathrm{CH})_{\text {ar }}$, at $1107 \mathrm{~cm}^{-1}$ for the in-plane $\delta(\mathrm{CCH})_{\text {ar }}$ and at $940 \mathrm{~cm}^{-1}$ assigned to out-of-plane $\gamma(\mathrm{CCH})_{\mathrm{ar}}{ }^{1,3}$

\section{Thermal stability}

Thermal analysis of a representative sample of the synthesized compounds, Ce-BTC $36 \mathrm{~h} 130{ }^{\circ} \mathrm{C}$, is shown in Figure 5. The behavior of weight losses was in agreement to the results obtained by Almáši et al. ${ }^{1,3}$ The weight losses started at $50{ }^{\circ} \mathrm{C}$ and ended at $780{ }^{\circ} \mathrm{C}$, approximately. The first decomposition step was observed up to $80^{\circ} \mathrm{C}$, with a weight loss of $5.57 \%$, corresponding to elimination of adsorbed water. The next four decomposition steps were observed up to $780{ }^{\circ} \mathrm{C}$, with a weight loss of $53.90 \%$ (calcd. $54.34 \%$ ), corresponding to partial elimination of one molecule of each coordinated water, DMF and BTC, in agreement with the molecular formula $\left\{\left[\mathrm{Ce}(\mathrm{BTC})\left(\mathrm{H}_{2} \mathrm{O}\right)\right] \cdot \mathrm{DMF}\right\}_{\mathrm{n}}$ used to calculate the reaction yield. ${ }^{1,3}$ The produced residue $(40.46 \%)$ was composed by a co-existence of amorphous components (carbon) remained and $\mathrm{CeO}_{2}$ (calcd. 41.16\%). The chemical composition of $\mathrm{CeO}_{2}$ in the residue was confirmed by PXRD and its diffraction pattern matched the simulated pattern (Figure S3, SI section). ${ }^{30}$

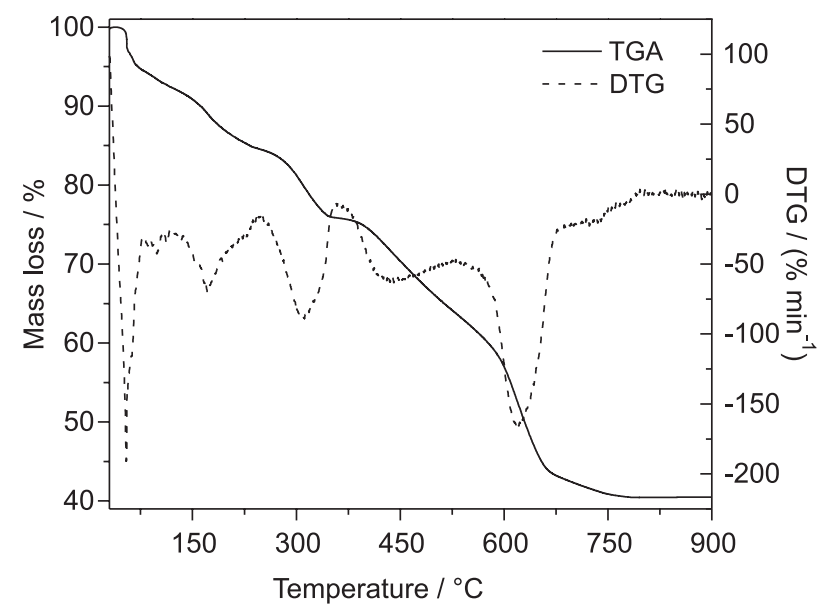

Figure 5. TGA/DTG curves of Ce-BTC 36 h $130{ }^{\circ} \mathrm{C}$ acquired under argon atmosphere.

\section{Particles morphology}

The morphology of Ce-BTC particles was investigated 

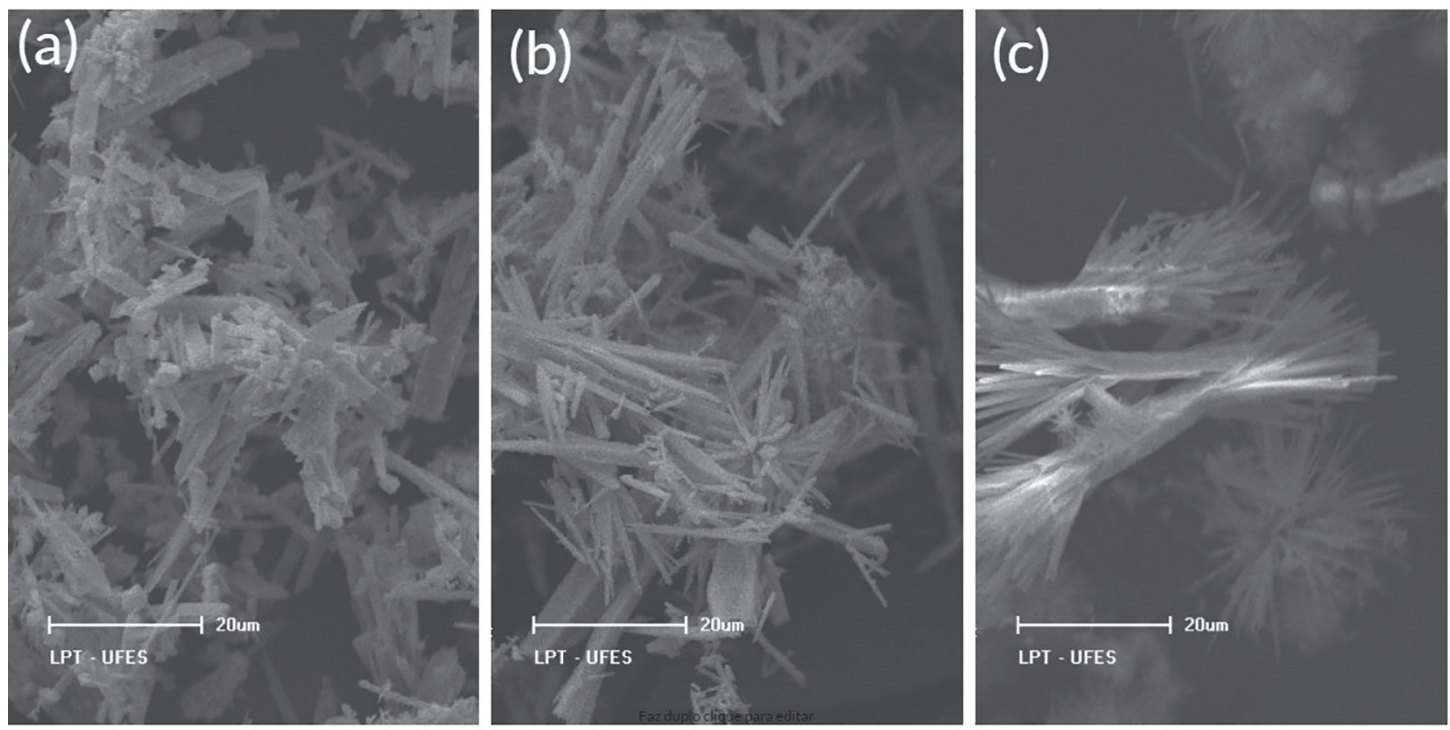

Figure 6. SEM images of Ce-BTC samples synthesized for $36 \mathrm{~h}$ at (a) 100 ; (b) 115 and (c) $130^{\circ} \mathrm{C}$.

by SEM. As the temperature was the most influential factor in the reaction yield, the compounds synthesized at different temperatures for $36 \mathrm{~h}$ were analyzed and images are shown in Figure 6. As it is possible to see, the temperature not only affected the yield, but also contributed for producing particles with different shapes. As reported by Chevinly et al., ${ }^{11}$ SEM images of the sample produced at $100{ }^{\circ} \mathrm{C}$ exhibited rod-like particles (Figure 6a). At $115^{\circ} \mathrm{C}$ (Figure 6b) structures like needle started being formed at the end of rods, and at $130{ }^{\circ} \mathrm{C}$ (Figure $6 \mathrm{c}$ ) the rods exhibited a greater number of needles, forming strawsheave-like structures, in agreement with the particles shape produced by Zhang et al. ${ }^{18}$ Therefore, the synthesis temperature was a key factor for obtaining Ce-BTC with strawsheaves structure, as well improving homogeneity of size and shape and decreasing the average size of the obtained particles, specially from 100 to $115^{\circ} \mathrm{C}$, as seen in Figure 6 .

To demonstrate the greater influence of temperature on the particles morphology, the sample Ce-BTC $12 \mathrm{~h} 130{ }^{\circ} \mathrm{C}$ was also analyzed by SEM and its image is presented in Figure 7. Comparing the image in Figure 7 to Figure 6c, both samples prepared at $130{ }^{\circ} \mathrm{C}$, but at different reaction times, 12 and $36 \mathrm{~h}$, respectively, they exhibited strawsheavelike structure confirming temperature as the most important factor for controlling particles shape.

\section{Sorption properties}

BET method is an important technique for measuring specific surface area $\left(\mathrm{S}_{\mathrm{BET}}\right)$ and porosity of solid materials based on the physical adsorption of gas molecules on their surfaces. In this sense, nitrogen adsorption isotherms at $-196{ }^{\circ} \mathrm{C}$ were measured for Ce-BTC $36 \mathrm{~h} 100^{\circ} \mathrm{C}$, Ce-BTC

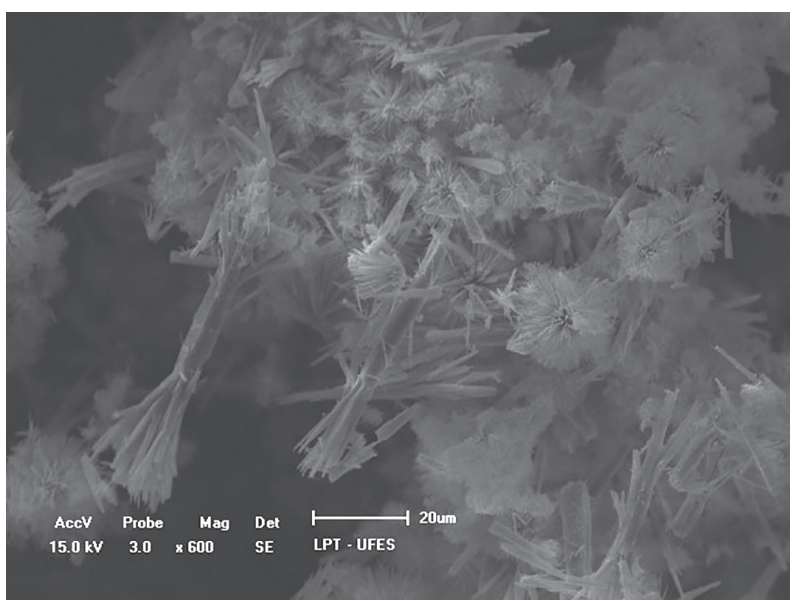

Figure 7. SEM image of Ce-BTC $12 \mathrm{~h} 130{ }^{\circ} \mathrm{C}$.

$36 \mathrm{~h} 115^{\circ} \mathrm{C}$ and Ce-BTC $36 \mathrm{~h} 130{ }^{\circ} \mathrm{C}$ and the results are shown in Figure 8. All samples showed an increase on the volume of adsorbed gas as relative pressure $\left(\mathrm{P} / \mathrm{P}_{0}\right)$ values increased, so obtained isotherms can be described as type I and the materials were microporous, according to IUPAC classification. ${ }^{31}$ The $S_{\mathrm{BET}}$ increased as the synthesis temperature increased. Synthesis at $100{ }^{\circ} \mathrm{C}$ produced particles with $\mathrm{S}_{\mathrm{BET}}$ of $3.95 \mathrm{~m}^{2} \mathrm{~g}^{-1}$. But, at 115 and $130^{\circ} \mathrm{C}$, the produced compounds showed $\mathrm{S}_{\mathrm{BET}}$ around 5.75 times bigger, exhibiting values of 24.13 and $21.91 \mathrm{~m}^{2} \mathrm{~g}^{-1}$, respectively. These apparently low values might had been caused by the absence of further heat treatment and the degassing process performed at $90{ }^{\circ} \mathrm{C}$ for $4 \mathrm{~h}$. A low $\mathrm{S}_{\text {BET }}\left(42 \mathrm{~m}^{2} \mathrm{~g}^{-1}\right)$ was also obtained by Zhang et al. ${ }^{18}$ to a Ce-BTC sample, prepared at $130{ }^{\circ} \mathrm{C}$ for $24 \mathrm{~h}$, but higher values were achieved when this sample underwent heat treatment $\left(\mathrm{T}>250{ }^{\circ} \mathrm{C}\right)$. Chevinly et al. ${ }^{11}$ evaluated the effect of degassing temperature on the surface area and 
found out an increase on $\mathrm{S}_{\mathrm{BET}}$ value as the temperature increased. $\mathrm{S}_{\mathrm{BET}}$ close to zero was obtained with a degassing performed at $160{ }^{\circ} \mathrm{C}$, but this value increased to $400 \mathrm{~m}^{2} \mathrm{~g}^{-1}$, approximately, at $300{ }^{\circ} \mathrm{C} .{ }^{11}$ Finally, the $\mathrm{S}_{\mathrm{BET}}$ measurements were in agreement with SEM images (Figure 6), which showed a decreasing in particles size as the temperature increased from 100 to $115^{\circ} \mathrm{C}$.

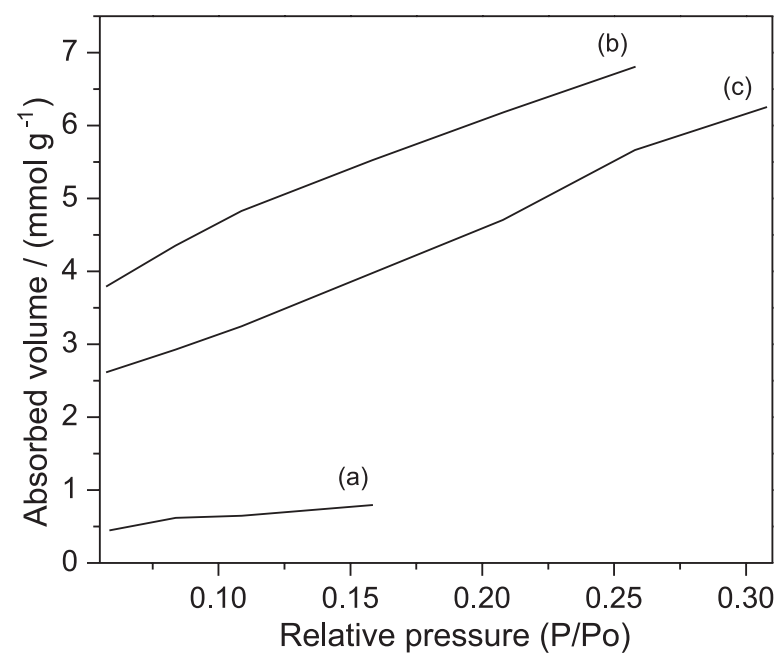

Figure 8. Nitrogen adsorption isotherms of (a) Ce-BTC 36 h $100{ }^{\circ} \mathrm{C}$; (b) Ce-BTC $36 \mathrm{~h} 115^{\circ} \mathrm{C}$ and (c) Ce-BTC $36 \mathrm{~h} 130{ }^{\circ} \mathrm{C}$.

\section{Conclusions}

This was an innovative work dedicated to optimizing the synthesis of a $\mathrm{Ce}^{3+}$-based MOF-76, since a factorial design was performed for this MOF for the first time. In this sense, a total of nine syntheses were executed combining time and temperature values and all of them successfully led to $\left\{\left[\mathrm{Ce}(\mathrm{BTC})\left(\mathrm{H}_{2} \mathrm{O}\right)\right] \cdot \mathrm{DMF}\right\}_{\mathrm{n}}$, as confirmed by IR spectroscopy, TGA and PXRD, once their results were compared to published works. Temperature was the parameter that affected the reaction yield the most. Yield values higher than $90 \%$ were achieved for reactions performed at $115{ }^{\circ} \mathrm{C}$ for, at least, $24 \mathrm{~h}$. SEM and BET results agreed with the literature and showed, respectively, a decrease on particle size and an increase on $\mathrm{S}_{\mathrm{BET}}$ as the temperature increased.

\section{Supplementary Information}

Supplementary data (FTIR spectra, PXRD and SEM images) are available free of charge at http://jbcs.sbq.org.br as PDF file.

\section{Acknowledgments}

The authors thank the Brazilian agencies FAPES
(Fundação de Amparo à Pesquisa do Estado do Espírito Santo) for financial scholarship. The authors also thank NCQP (Núcleo de Competências em Química do Petróleo) for PXRD and IR spectroscopy analyses, LPT (Laboratório de Plasma Térmico) for SEM images and LMC (Laboratório de Materiais Carbonosos e Cerâmicos) for TGA and nitrogen adsorption measurements.

\section{References}

1. Almáši, M.; Zelenák, V.; Opanasenko, M.; Císarová, I.; Catal. Today 2015, 243, 184.

2. Horike, S.; Kitagawa, S. In Metal-Organic Frameworks. Applications from Catalysis to Gas Storage, $1^{\text {st }}$ ed.; Farrusseng, D., ed.; Wiley-VCH Verlag GmbH \& Co. KGaA: Villeurbanne, France, 2011, p. 3.

3. Almáši, M.; Zelenák, V.; Kuchár, J.; Bourrelly, S.; Llewellyn, P. L.; Colloids Surf., A 2016, 496, 114.

4. Ren, Y.; Chia, G. H.; Gao, Z.; Nano Today 2013, 8, 577.

5. Eddaoudi, M.; Moler, D. B.; Li, H.; Chen, B.; Reineke, T. M.; O'Keeffe, M.; Yaghi, O. M.; Acc. Chem. Res. 2001, 34, 319.

6. Jahan, M.; Liu, Z.; Loh, K. P.; Adv. Funct. Mater. 2013, 23, 5363.

7. Gao, X.; Zhao, H.; Zhao, X.; Li, Z.; Gao, Z.; Wang, Y.; Huang, H.; Sens. Actuators, B 2018, 266, 323.

8. Horcajada, P.; Serre, C.; Vallet-Regí, M.; Sebban, M.; Taulelle, F.; Férey, G.; Angew. Chem., Int. Ed. Engl. 2006, 45, 5974.

9. Ibrahim, M.; Sabouni, R.; Husseini, G. A.; J. Nanosci. Nanotechnol. 2018, 18, 5266.

10. Faradonbeh, M. R.; Dadkhah, A. A.; Rashidi, A.; Tasharofi, S.; Mansourkhani, F.; J. Inorg. Organomet. Polym. Mater. 2018, $28,829$.

11. Chevinly, A. S.; Mobtaker, H. G.; Yousefi, T.; Shirani, A. S.; Aghayan, H.; Inorg. Chim. Acta 2017, 455, 34.

12. Rosi, N. L.; Kim, J.; Eddaoudi, M.; Chen, B.; O’Keeffe, M.; Yaghi, O. M.; J. Am. Chem. Soc. 2005, 127, 1504.

13. Gustafsson, M.; Bartoszewicz, A.; Martín-Matute, B.; Sun, J.; Grins, J.; Zhao, T.; Li, Z.; Zhu, G.; Zou, X.; Chem. Mater. 2010, 22, 3316 .

14. Jiang, H.; Tsumori, N.; Xu, Q.; Inorg. Chem. 2010, 49, 10001.

15. Guo, X.; Zhu, G.; Li, Z.; Sun, F.; Yang, Z.; Qiu, S.; Chem. Commun. 2006, 30, 3172.

16. Peng, M. M.; Ganesh, M.; Vinodh, R.; Palanichamy, M.; Jang, H. T.; Arabian J. Chem. DOI: 10.1016/j.arabjc.2014.11.024.

17. Zhang, X.; Hou, F.; Yang, Y.; Wang, Y.; Liu, N.; Chen, D.; Yang, Y.; Appl. Surf. Sci. 2017, 423, 771.

18. Zhang, X.; Hou, F.; Li, H.; Yang, Y.; Wang, Y.; Liu, N.; Yang, Y.; Microporous Mesoporous Mater. 2018, 259, 211.

19. Elhussein, E. A. A.; Şahin, S.; Bayazit, S. S.; J. Mol. Liq. 2018, $255,10$. 
20. Zeng, G.; Chen, Y.; Chen, L.; Xiong, P.; Wei, M.; Electrochim. Acta 2016, 222, 773.

21. Statistica (Data Analysis Software System), version 12; StatSoft, Inc., Tulsa, OK, USA, 2014.

22. Luo, J.; Xu, H.; Liu, Y.; Zhao, Y.; Daemen, L. L.; Brown, C.; Timofeeva, T. V.; Ma, S.; Zhou, H.; J. Am. Chem. Soc. 2008, $130,9626$.

23. Momma, K.; Izumi, F.; J. Appl. Crystallogr. 2011, 44, 1272.

24. Fonseca, R. R. F.; Gaspar, R. D. L.; Raimundo Jr., I. M.; Luz, P. P.; J. Rare Earths 2019, 37, 225.

25. Khan, N. A.; Haque, M. M.; Jhung, S. H.; Eur. J. Inorg. Chem. 2010, 31, 4975.

26. Chris, J. J.; Basic Concepts in Chemistry, $d$ and f-Block Chemistry, $1^{\text {st }}$ ed.; Wiley-RSC: New York, USA, 2002.
27. Chuasaard, T.; Panyarat, K.; Rodlamul, P.; Chainok, K.; Yimklan, S.; Rujiwatra, A.; Cryst. Growth Des. 2017, 17, 1045.

28. Silverstein, R. M.; Webster, F. X.; Kiemle, D. J.; Spectrometric Identification of Organic Compounds, $7^{\text {th }}$ ed.; John Wiley \& Sons: New York, USA, 2005.

29. Łyszczek, R.; Mazur, L.; Rzaczynska, Z.; Inorg. Chem. Commun. 2008, 11, 1091.

30. Wyckoff, R. W. G.; Crystal Structure, vol. 1, $2^{\text {nd }}$ ed.; 1963, Interscience Publishers: New York, USA, p. 239.

31. Sing, K. S. W.; Everett, D. H.; Haul, R. A. W.; Moscou, L.; Pierotti, R. A.; Rouquérol, J.; Siemieniewska, T.; Pure Appl. Chem. 1985, 57, 603. 